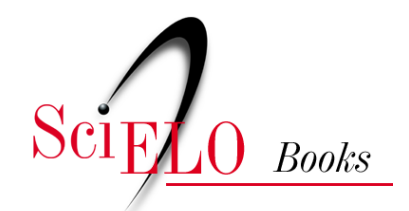

\title{
O ensaio de Eduardo Prado na Revista de Portugal anterior à publicação de Fastos da ditadura militar no Brasil
}

\author{
Éverton Barbosa Correia
}

\section{SciELO Books / SciELO Livros / SciELO Libros}

CORREIA, É.B. O ensaio de Eduardo Prado na Revista de Portugal anterior à publicação de Fastos da ditadura militar no Brasil. In: WERKEMA, A.S., ROCHA, F.C.D., and OLIVEIRA, L.D., eds. Literatura brasileira em foco VIII: outras formas de escrita [online]. Rio de Janeiro: EdUERJ, 2018, pp. 78-98. ISBN 978-85-7511-487-2. https://doi.org/10.7476/9788575114872.0006.

All the contents of this work, except where otherwise noted, is licensed under a Creative Commons Attribution 4.0 International license.

Todo o conteúdo deste trabalho, exceto quando houver ressalva, é publicado sob a licença Creative Commons Atribição $\underline{4.0}$.

Todo el contenido de esta obra, excepto donde se indique lo contrario, está bajo licencia de la licencia Creative Commons $\underline{\text { Reconocimento 4.0. }}$ 
Éverton Barbosa Correia

O ensaio de Eduardo Prado na Revista de Portugal anterior à publicação de Fastos da ditadura militar no Brasil 
A imagem de Eduardo Paulo da Silva Prado que chega até nós é a de um autor plenamente identificado com a monarquia, menos pela adesão a seu ideário do que pela reação ostensiva e sistemática à governança republicana recém-instalada no poder. A virulência de sua reação tem as motivações das mais variadas ordens, pois é bem sabido que Dom Pedro II frequentava a casa de sua mãe, Dona Veridiana, plantada numa rua do bairro paulistano de Santa Cecília, a qual atualmente recebe o nome da matriarca. A informação interessa para que possamos dimensionar melhor o alcance da dinastia, em torno da qual se reunia a intelectualidade brasileira, circunstancialmente paulista, cujos interesses iriam redundar na semana de arte de 1922, hoje já dissociada da família, nem tão casualmente assim. $\mathrm{O}$ fato consumado é que o primogênito de Veridiana, Antonio Prado, senador e conselheiro do Império, viria a ser líder inconteste do Partido Republicano Paulista (PRP), o qual mesmo durante o regime monarquista alistava entre suas fileiras os irmãos do meio, Caio e Martinico, ficando o caçula com o encargo de seguir o seu destino, a contrapelo da família e de suas conveniências, tendo se tornado o militante antirrepublicano mais corrosivo (Nogueira, 2003). 
Polemista acirrado, pesquisador infatigável e cultíssimo, tudo que vertia de sua pena trazia o ressaibo da amargura que o novo regime havia instaurado. É sob tal tonalidade expressiva que se constitui a persona literária de Eduardo Prado, mais monarquista do que prosador, mais pesquisador do que escritor, mais ensaísta do que militante ativo, se quisermos lhe imputar adjetivos que concorram para sua identidade autoral. Mecenas pródigo, amigo de quase todos e filho de Veridiana, mulher e sobrinha de Martinho Prado, o qual, por sua vez, era meio irmão do barão de Iguape, primeiro Antonio da Silva Prado, a um só tempo avó materno e tio-avô paterno do escritor, cuja ramificação familiar se enraíza no império desde quando o príncipe regente começou a ir a São Paulo para encontrar Domitila do Castro e Silva. Já ali a família Silva Prado interferia no destino da pátria, conforme refere Sérgio Buarque de Holanda no "Prefácio" à biografia, intitulada $O$ barão de Iguape, comentando o relato do pai da Marquesa de Santos, amante do defensor perpétuo do Brasil.

$\mathrm{Na}$ descrição da viagem do príncipe regente D. Pedro a São Paulo, em 1822, que redigiu Francisco de Castro Canto e Melo, gentil-homem de sua câmara e futuro visconde de Castro, lê-se que o dito regente recebeu na capital paulista 'a obsequiosa e magnífica hospedagem que lhe haviam preparado o brigadeiro Manuel Rodrigues Jordão e o coronel Antonio da Silva Prado, hoje barão de Iguape.... Por onde se vê que esse relato, publicado por Melo Morais, foi composto depois de 1948, ano em que Prado foi barão (Holanda, 1976, p. XI).

A despeito da distância entre a recepção imperial e o recebimento do título nobiliárquico, percebe-se que Antonio da Silva Prado, avô do ensaísta, desde longas datas teve alguma penetração na cabeça do governo e na administração do Império. Inicialmente através dos segredos da alcova imperial, para se enraizar na governança brasileira muito além da monarquia, dispondo de um legado 
inquebrantável para sua descendência direta. Não estranha, a partir disso, que no mesmo seio familiar encontrem-se partidários da república - a pretexto de se manter no poder - e defensores da monarquia - com o propósito de resguardar a tradição, tão bem ilustrada pela endogamia cafeeira praticada nos ramos daquele clã, que passa da economia para a política sem dificuldade e resvala na representação literária. Se Eduardo Prado pode facilmente ser perfilado aí, nem por isso podemos incensar sua figura com aromas de conservadorismo, porque outra é a tonalidade de seu discurso e para outro sentido se imposta o timbre de sua voz, mesmo quando partidário lascivo da tradição luso-brasileira.

Desbastada sua participação na Exposição Universal de Paris de 1889, por meio de ensaio sobre a história literária brasileira, intitulado "A língua e a literatura" (Prado, 2000, pp. 126-9), que veio a constar no livro Brésil - aqui citado em tradução e organizado por Emile Levasseur - , conviria destacar, porém, que sua internacionalização autoral se deu sob o crivo de Eça de Queirós, editor da Revista de Portugal, onde figuravam autores que vieram a constituir o panteão português, ilustrado por Ramalho Ortigão, Theófilo Braga ou Fialho de Almeida, bem como por brasileiros notáveis, mas ainda não devidamente consagrados. Até porque, em 1889, quando se inicia aquela publicação, a Academia Brasileira de Letras (ABL) ainda não existia, de onde viriam a se tornar membros os eventuais colaboradores brasileiros daquele periódico, a exemplo de Oliveira Lima, Medeiros e Albuquerque, além do próprio Eduardo Prado, ora identificado pelo pseudônimo Frederico de S. e ora assumindo sua identidade autoral. E ainda que saibamos hoje que Eduardo Prado e Frederico de S. se tratam de duas faces da mesma autoria, não foi como uma unidade autoral que sua obra foi publicada e recebida à sua época. Tanto é que, quando convertido em livro autônomo, pu- 
blicado sob o mesmo selo da Revista de Portugal, os artigos reunidos foram somente aqueles que haviam sido atribuídos a Frederico de S., que continuou a identificar a autoria, sem que o artigo assinado por Eduardo Prado fosse recolhido ali, embora constasse na primeira versão da Revista de Portugal, tal como foi organizada por Eça de Queirós. Como aquele artigo identificado pelo nome de Eduardo Prado jamais foi coligido ou publicado, apesar das reiteradas edições do volume Fastos da ditadura militar no Brasil, por isso, será o que terá precedência no argumento a se desenrolar aqui.

Acompanhando os quatro volumes constitutivos da Revista de Portugal, dispomos dos seguintes artigos assinados ou atribuídos por pseudônimo a Eduardo Prado, conforme a ordem de publicação: no primeiro volume (Queirós, 1889) - "Destinos políticos do Brasil” e "Os acontecimentos no Brasil"; no segundo volume (Queirós, 1890a) - "Os acontecimentos no Brasil", "O Brasil, fastos da ditadura", "A ditadura no Brasil, tratados diplomáticos e crédito financeiro", "As finanças e a administração da ditadura brasileira", "A república brasileira"; no volume terceiro (Queirós, 1890b) não consta nenhum artigo sob autoria de Eduardo Prado, nem pelo seu nome nem pelo seu pseudônimo; no quarto volume (Queirós, 1892), aparece este título: "Práticas e teorias da ditadura militar no Brasil". Dessa descrição, podemos depreender algumas informações, tais como a de que existe uma concentração maior de artigos no volume II, publicado 1890, no mesmo ano de publicação do livro Fastos da ditadura militar no Brasil, também editado pelos mesmos Lugan e Genelioux, responsáveis pela publicação do periódico, sucessores de Chardron, conforme está timbrado no seu frontispício. A considerar a coincidência de data e de editores, é bem possível que os artigos tenham ido ao prelo uma única vez para constar em ambas as publicações, como colaboração da Revista de Portugal e como autoria autônoma sob 
o novo título de Fastos da ditadura militar no Brasil, tragado de um dos capítulos supracitados e reunidos na Revista de Portugal, a saber, "O Brasil, fastos da ditadura” (Prado, 1890, pp. 240-58). É preciso registrar, ainda, que não só o título desse artigo sofreu alteração de uma publicação para outra, mas todos os demais, sem interferência nos respectivos conteúdos apresentados, de parte a parte, mantendo-se o mesmo texto em ambas as publicações. A mudança da coleção de artigos reunidos - seja por uma autoria única, seja por vários autores - haverá de incidir sobre a compreensão do enunciado como um todo, mas sem repercussão no conteúdo particular daqueles artigos. A variação mínima de título permite fácil identificação dos capítulos entre si, quer tomemos como referência a publicação coletiva portuguesa ou a publicação individual do autor brasileiro.

A diferença entre as duas publicações ficaria por conta de dois artigos: o primeiro é "Destinos políticos do Brasil", assinado por Eduardo Prado e coligido no volume I da Revista de Portugal, mas que não foi incorporado ao livro timbrado sob pseudônimo; e o outro, do artigo "Práticas e teorias da ditadura republicana no Brasil", somente publicado no volume IV daquele mesmo periódico, que só veio a lume em 1892, quando a governança republicana já estava consolidada e dois anos após aquela publicação autoral identificada por Frederico de S. Talvez assim tenha sido feito para não revelar de pronto a identidade autoral, que oscilava entre seu nome próprio e o daquele seu pseudônimo já constante no primeiro volume do periódico, o qual passou a comparecer pontualmente nos volumes seguintes, nos quais o nome de Eduardo Prado desaparece e o de Frederico de S. cresce, inclusive pela quantidade de páginas de cada um dos artigos do segundo volume, que se destacam consideravelmente dos artigos do primeiro, tanto daquele assinado pelo autor quanto o outro sob seu pseudônimo. 
Se a identificação autoral daquele primeiro artigo coligido na Revista de Portugal foi o motivo de sua exclusão do livro identificado por Frederico de S., sua condição de preventivo do que viesse viger no Brasil como regime político salta aos olhos, considerando que a produção literária ainda servia de veículo para o embate político. Fosse como fosse, aquele artigo da Revista de Portugal não viria a constar na primeira publicação de Fastos da ditadura militar no Brasil e, por consequência, nem em qualquer outra, mesmo depois de revelada a identidade autoral e tornado possível o cotejo entre ambas as publicações. Com isso, o artigo acaba adquirindo a feição de discurso particularizado pela autoria ali circunstanciada e, por conseguinte, não será tomado tão só como mais um artigo de Eduardo Prado na Revista de Portugal e nem como um capítulo de Fastos da ditadura militar no Brasil, o que efetivamente não foi até o momento e possivelmente nunca virá a ser, a despeito da identidade autoral ali constituída e da contiguidade dos demais artigos do mesmo autor. Por uma razão ou por outra, será tomado como um ensaio individualizado que, por sua vez, empresta conotação peculiar ao seu pronunciamento, a considerar as particularidades de sua veiculação. Por outro lado, se tomarmos Fastos da ditadura militar no Brasil como uma publicação autônoma, assinada por um pseudônimo, o livro mantém a mesma disposição e configuração inicial, embora não pudesse cumprir de todo o anúncio de seu subtítulo "artigos publicados na Revista de Portugal", ao menos se considerarmos a figura solar de seu autor, que se autonomeia e se traveste com outro nome na mesma publicação.

Sendo explicável a ausência daqueles artigos na publicação que se prestava a reunir artigos contíguos e similares entre si, sob uma autoria determinada, nada justifica a falta de menção nas edições posteriores de Fastos da ditadura militar no Brasil, até porque 
aquela ditadura, circunstancialmente nomeada, deixou de ser qualificada como "militar" e passou a ser "republicana", conforme enunciação dos próprios títulos dos artigos, o que permitiria ao menos uma visão perspectivada do processo descrito como um todo pelo autor. De qualquer modo, ambos os artigos deslocados da publicação merecem tratamento diferenciado, menos por alguma divergência discursiva em relação ao livro como uma totalidade portadora de sentido, do que pela possibilidade de oferecer uma compreensão mais aproximada do seu valor ou do seu interesse naquele momento primeiro de sua publicação. Pairando entre dois veículos autônomos entre si, mas que alvejavam igualmente a divulgação dos desmandos da governança brasileira, os dois artigos identificam a mesma persona autoral, ainda que bifurcada, já que podemos tomar a autoria de Eduardo Prado neles constituída pelo seu nome próprio e pelo seu pseudônimo, respectivamente. Todavia, há diferenças entre a circunstância de publicação e a circulação dos artigos, bem como entre a publicação dos artigos e a configuração do livro que enfeixa aqueles outros que lhe são contíguos no periódico português, excluindo-os no livro brasileiro. Essas diferenças ganharão relevo aqui pelo justo propósito de dimensionar o papel do autor no xadrez político nacional, que às vezes se estendia para além do Atlântico.

Cotejados entre si, na Revista de Portugal, os dois artigos preteridos da publicação de Eduardo Prado, ora apresentado como autor individualizado ora como pseudônimo, constituem uma espécie de moldura do livro, cujo delineamento não está grafado na imagem que se descola do quadro apresentado. Fastos da ditadura militar no Brasil se oferece, segundo a perspectiva, como um quadro sem a moldura que o define como um objeto estético circunstanciado. E a hipótese aventada aqui é a de que olhando para a moldura do quadro, ou parte dela, possamos analisar pela parte escolhida a imagem 
que o quadro se nos compunha por completo, como se pudéssemos, retrospectivamente, aferir algumas condicionantes de sua publicação e, a partir daí, ter uma experiência estética mimeticamente deslocada ou, ao menos, conferir-lhe um valor a partir dos termos de sua proposição inicial. Para tanto, deter-nos-emos, exclusivamente, ao primeiro texto na ordem de publicação da Revista de Portugal, que é "Destinos políticos do Brasil" (Prado, 1889, pp. 467-91), assinado por Eduardo Prado propriamente e publicado quando recém-proclamada a República. A duplicidade autoral de Eduardo Prado permite a visualização dos artigos autonomamente e será esta a vertente de leitura dominante a ser praticada aqui, muito embora também possam ser vistos como desdobramentos de uma mesma persona autoral, que incide diversamente sobre momentos distintos da virada republicana, a considerar que seu último artigo na Revista de Portugal só veio a ser publicado no último volume, editado em 1992, quando o regime já estava consolidado. Até porque, num primeiro momento, convinha ao autor se apresentar em primeira pessoa, ao passo que a consolidação do regime fez com que o autor se desdobrasse num outro de si, expressando-se em outra voz, supostamente alheia à sua, mas nem tanto assim.

Passemos, pois, à análise do artigo "Destinos políticos do Brasil", que se estende ao longo de 24 páginas da Revista de Portugal, portanto, com uma extensão bem maior do que o seu sucessor imediato “Os acontecimentos do Brasil” (Prado, 1889, pp. 770-6), o qual encerra sua exposição em seis páginas do mesmo volume, que marca a passagem da autoria individualizada para a do pseudônimo. $\mathrm{Da}$ quele primeiro texto, em que o autor ainda se assina como Eduardo Prado, podemos destacar duas interrogações iniciais que movem o escrito: "continuará a existir a Monarquia? Continuará a existir unido o Brasil?" As duas questões exercem funções nucleares ao longo 
do ensaio, porque, àquelas alturas, ainda não era certo que o regime monárquico houvesse se dissolvido definitivamente e a associação da integridade nacional à monarquia era o raciocínio a ser lançado de pronto, mesmo porque não havia até então outra experiência histórica gravada no chão luso-americano. Acresce a isso o fato de que a América hispânica havia se repartido num sem-número de repúblicas acaudilhadas por interesses obscuros e cujo saldo imediato era o da desvinculação entre a colônia e a metrópole. Como as colônias do Brasil e do Maranhão e Grão-Pará se emanciparam sob a chancela da dinastia bragantina, a qual continuou a governar o país unido e emancipado, soava bastante estranho uma ruptura brusca, inclusive porque, por meio da política moderada, poderiam ser identificados os possíveis elementos constitutivos de uma hipotética tradição, associada à sociabilidade encostada na religião católica, à língua portuguesa aclimatada aos trópicos ou à administração pautada por costumes lusos. Conforme fosse, o Brasil ainda figurava um braço de Portugal estendido ao mundo, em cuja extensão o autor se empenha em enxergar uma tradição constituída.

Observando o ensaio em perspectiva, é possível enxergar um movimento duplo que lhe vem a ser constitutivo. Dividido em duas partes, a primeira se volta para demonstração da insuficiência argumentativa e do esvaziamento de propósitos dos republicanos, cujo ancoradouro viria a ser uma classe média parasitária, constituída basicamente de bacharéis que dariam sustentação jurídica e retórica à decadência do latifúndio, ressentido com a política emancipatória monarquista. Enquanto que, na segunda parte, o eixo dos comentários seria pautado pelas falhas da monarquia parlamentarista, que se convertiam em alvo fácil para a retórica de ocasião dos republicanos se atracar como se em um porto seguro para defenestrar todo o aparelho do incipiente estado brasileiro. Confrontadas 
entre si, as duas partes sugerem algum tipo de correção daquele golpe insurrecional que parecia incompatível com a dinâmica institucional vigente no Brasil até aquelas alturas, bem como com as práticas sociais aclimatadas ao chão brasileiro ao longo do século XIX, que serviam de suporte para a visualização de uma possível tradição enraizada na colonização lusitana, da qual decorreria inclusive a forma monárquica. Cumpre assinalar o veio ensaístico que anima o seu escrito, cuja ambiência é dada pelo famoso quadro de Pedro Américo que ilustra o momento da Proclamação da Independência, retomando a um só tempo a emancipação nacional e o vínculo com a dinastia bragantina, inscrita na figura de D. Pedro I, em torno de quem aparecem os soldados e, num círculo mais amplo, os pardos e desbotados do processo social, pouco afeitos e familiarizados com intempéries políticas, nas quais se constituem como elemento fosco e obscuro, sem intervenção nos acontecimentos, tal como ali estão cinzelados.

Um pintor brasileiro, Pedro Américo, no seu quadro A proclamação da Independência do Brasil, retraçou o fato com toda verdade e toda filosofia. Vê-se nessa pintura o príncipe regente, a cavalo, de espada desembainhada, cercado de sua guarda de honra, dos gentis-homens da sua câmara, de vários capitães-mores e de oficiais de ordenanças. Os couraceiros, os oficiais, os da corte brandem as espadas ou agitam os chapéus e no quadro há a vida admirável daquele momento histórico. A um canto, um homem de cor guiando um carro, arreda os seus bois da estrada e olha admirado para o grupo militar; ao longe, destacando-se no fundo iluminado duma tarde que cai sobre a paisagem melancólica, um homem do campo, um caipira retém o passo à cavalgadura e voltando tranquilamente o rosto vê, de longe, a cena que não compreende. Esses dois homens são o povo brasileiro, o povo real, a maioria da população que não participou da independência e muito menos toma parte na agitação republicana promovida em torno dele (Prado, 1989, pp. 470-1). 
Não deixa de ser curioso que, para desenvolver um ensaio político e histórico, o autor tenha escolhido como ponto de apoio a cena esculpida num quadro, indiscutivelmente definido como um objeto artístico e assim é reconhecido. O ensaísta parece acreditar no poder da arte de iluminar a história e orientar o seu presente. Reproduzida à exaustão, a cena hoje conhecida por todos os brasileiros - e à sua época certamente pelos brasileiros cultos - impressiona pela riqueza de detalhes e pelo poder de síntese da Proclamação da Independência do Brasil, que serve de índice para a Proclamação da República, conforme intuição autoral realizada primorosamente na descrição do quadro "Independência ou morte". Sobretudo quando dá visibilidade ao elemento marginal estampado na imagem, que, a contrapelo do movimento histórico, o quadro mostra através do caipira na sua cavalgadura e um homem de cor, arredando bois, sem o entendimento exato do que se passava ali. O episódio, de fato, se faz bastante ilustrativo dos processos históricos que animam a sociabilidade deitada no chão brasileiro, revelando-se em momentos decisivos da emancipação nacional, o que pode ser ilustrado em ambas as proclamações, a da Independência e a da República.

A centralidade do quadro de Pedro Américo, como se sabe, é dada pela figura do príncipe regente ali tornado simbolicamente rei e que provoca uma onda que serpenteia todos os dragões do império, o que pode ser percebido pelos movimentos de seus penachos e dos rabos de seus cavalos. Mas esse movimento não foi realçado pelo ensaísta, porque daria visibilidade à arbitrariedade da subida e da consagração imperial e porque reproduziria a marginalidade popular, inscrita no quadro, contra a qual se insurge, uma vez que se pretende identificar com o povo, que defende. Por isso, a sobreposição muito ligeira da figura imperial do quadro pelo republicano da ocasião de 
sua escrita, igualmente revolto por militares, parece forçosa se considerarmos tão somente a troca dos penachos por chapéus.

O mais curioso é que, ao longo do ensaio, a ênfase seja dada às figuras dos militares, dos bacharéis e dos proprietários de terra, ao contrário do que enfatiza no quadro, como se ali interessasse o elemento marginal a ser defendido, conforme um sintoma social, e na vida prática o elemento estruturador a ser denunciado e, possivelmente, combatido. Sem inverter os lugares postos no objeto artístico, o que ali é contingente e acidental não ganha lugar de destaque no corpo do ensaio. Mas com o fito de acompanhar sua descrição dos tipos sociais atuantes naquela narrativa, comecemos pela figura dos bacharéis que tampouco aparecem com nitidez no quadro de Pedro Américo. Por outra, constituem-se como elemento estranho à representação pictórica que deu ensejo ao ensaio, mas que servem exemplarmente para sua denúncia.

O que se está chamando no Brasil o movimento republicano é um movimento de descontentes, todos formando uma minoria na classe dos privilegiados possuidores de terra ou dos indivíduos a quem couberam parcelas de instrução superior - homens feudais ou homens de pena - colocados acima do pobre ou do iletrado. [...] Os bacharéis constituem quase exclusivamente a classe dos políticos. Ora, a política vem a ser, em toda a parte, mais ou menos, a arte de ganhar eleições e de obter empregos. No Brasil, o caso agrava-se porque a deficiente organização social e econômica não dá às atividades as ocasiões de sucesso normalmente possíveis no comércio, nas indústrias (Prado, 1889, p. 471).

Se na descrição do quadro de Pedro Américo parecia natural ao ensaísta que sobrepusesse o movimento da espada do republicano ao do primeiro império brasileiro, agora aqueles mesmos republicanos são aproximados da figura do bacharel, excluído da pintura oitocentista, mas não da governança brasileira, para a qual o serviço 
público funcionava como ancoradouro dos letrados descontentes. À falta de sucesso no comércio e na indústria corresponde um inchaço na vida pública, que se traduz inclusive em elemento verbal, organizado retoricamente. Decerto Eduardo Prado se sentia muito à vontade para fazer tais afirmações, visto que, sendo bacharel por formação e parte de uma família que esteve à frente da exportação do café numa época em que representava algo como $75 \%$ da receita brasileira (Levi, 1977, pp. 159-60), estava autorizado a fazê-lo. Todo o seu repertório o levaria a dizer com precisão quais os entraves do comércio exterior, bem como seu correspondente limitante da indústria nacional. Irmão de Conselheiro do Império, convertido em líder republicano, e de republicanos ativos quando ainda da vigência da monarquia, sua fala adquire valor representativo, mesmo por ocasião da sobreposição de espadas - fossem imperiais ou republicanas - ao menos como uma experiência familiar com a qual nunca se identificou de todo, embora tampouco conseguisse suprimir de uma vez só, tal como quando descreve os partidos de então.

Os partidos estão convencidos da inutilidade de todos os seus esforços pela conquista do poder, se em socorro deles não vier a intervenção imperial. Daí resultam a fraqueza das oposições, a insolência dos governos e a situação falsa e desmoralizada dos chefes políticos, dependendo diretamente, não do corpo eleitoral, mas do Imperador, eixo único do estado, em torno do qual gira toda a máquina da vasta monarquia brasileira. [...] O mal está em não se haver o povo educado na época própria, está no hábito adquirido. O que podia ser tolerado como uma exceção temporária no sistema de governo, tornou-se a essência mesma do governo. Os homens mais eminentes do Brasil tem atribuído sem razão a permanência desta monstruosidade constitucional do Imperador, quando é evidente que ele só não pode transformar num povo livre um eleitorado, cuja maioria vota sempre com o governo. Muito menos pode o Imperador, sem a cumplicidade dos políticos, manter a sua exprobrada onipotência (Prado, 1889, p. 473). 
Ao que parece, a ideia de povo acionada anteriormente não se reproduz aqui, uma vez que o povo nomeado agora está associado aos políticos como seus legítimos representantes. Representantes vinculados a partidos que se submeteram a relações viciosas com o governo, as quais, justificáveis como atos de momento, sedimentaram práticas que se fizeram regulares, encalacrando num labirinto sinuoso o Imperador e os representantes partidários, sem os quais a governança não seria possível. Colados na orientação imperial, não havia meio de pensar outra alternativa àquele sistema, senão pela deposição da sua figura central, que chamava para si toda sorte de responsabilidades, agraciando ocasionalmente a uns e desagradando sempre a maioria. Como a substituição do imperador não resolveria o impasse, o raciocínio imediato seria o de substituir integralmente o sistema, e não apenas uma de suas partes. Por esta outra angulação, os argumentos de Eduardo Prado parecem convincentes sobretudo se considerarmos o público a que ele se dirigia.

O bacharel, a entidade falante e escrevente no meio brasileiro, nem sempre pode ser empregado, nem sempre pode tirar lucros da vida de advogado. Pode, porém, ser republicano, isto é, falar do povo em nome dele povo, sem que este ouça ou o tenha nomeado seu representante. [...] Muitos dos antigos proprietários de escravos, devedores insolváveis dos bancos e dos capitalistas, condição que já muito os dispunha para o papel de descontentes, injuriam a monarquia pelo crime imperdoável de haver presidido à liberdade dos escravos. O bacharel é o porta-voz do escravista despeitado. A vingança de um quer ser servida pela ambição de outro. Um quer destruir a monarquia que lhe tirou o negro, outro, parasita social improdutivo, cliente devendo obediência ao patrono, verdadeiro escravo a quem não aproveitou a abolição, escravo sabendo gramática e entendendo de lei, como os tinham os grandes romanos, esse bacharel, sicário movido do ódio alheio, quer tirar proveito de alguma coisa nova que surja no estado. Por trás do orador, do jornalista, está muitas vezes o antigo e incipiente senhor de es- 
cravos transformado em apóstolo de todas as liberdades, exceto a do governo (Prado, 1889, pp. 474-5).

Qualificado como entidade falante e escrevente, o bacharel ilustra um tipo social cuja função linguística é mais instrumental do que afirmativa de uma condição, mesmo quando articula a palavra "liberdade" como uma reivindicação sua. O argumento perfilado sem meias tintas por Eduardo Prado tanto mais adquire valor de verdade, quanto mais assinalarmos sua tonalidade expressiva, para a qual o estilo prefigura um posicionamento político mais reflexivo do que conformado e, contraditoriamente, mais conservador de uma hipotética tradição existente no solo luso-brasileiro do que entusiasta de licenciosidades republicanas, validas de armas que se escudam no interesse popular. Sem hesitar sobre quem seria o beneficiário das liberdades apregoadas, conviria lembrar que seu lugar social era o da gente majoritariamente responsável pela expansão cafeeira para o oeste paulista, cujo exemplo dado pela sua família dispunha sobejamente de vários tipos sociais, todos eles decorrentes da condição básica de ser bacharel, o que se aplica inclusive ao próprio ensaísta indignado, que via com horror o braço armado do Estado se voltar contra a autoridade imperial.

Os republicanos, desejando mudar a forma de governo do país porque a monarquia não é bastante liberal, e desejando restaurar a liberdade política, pensam assegurá-la por meio de uma insurreição militar. Os restauradores da dignidade cívica dos cidadãos aceitam a república nascida da indisciplina dos quartéis. Esta indisciplina é todos os dias insuflada à tropa pelos jornais republicanos; qualquer oficial pouco respeitoso aos seus superiores é incensado e engrandecido; qualquer veleidade de caudilhismo manifestada por um general ignorante é logo afagada e um simples sargento, desde que é insubordinado é um longo herói, com que a causa republicana pode e deve contar. É fácil avaliar o perigo para a civilização brasileira dum conflito entre a tropa e o regime legal (Prado, 1889, pp. 477-8). 
É espantosa a verticalidade do argumento, porque descreve aquela circunstância e adverte, ao mesmo tempo, do perigo a que o país estaria exposto com a aceitação daquelas práticas. Torna-se imperativo lembrar que a insubordinação militar passou a vigorar no espaço social e político brasileiro, a partir de então, como um critério de verdade incontornável, a considerar toda sorte de "tenentismo" que animou a chamada República velha, e mesmo quando convertida em nova República o aparato militar se viu autorizado a intervir na ordem social e política sempre que houvesse qualquer laivo de desordem ou os interesses dos descontentes pudessem ser contemplados em detrimento da ordem, ocasionalmente democrática. Daí a força do argumento se inscrever menos no seu valor histórico, capaz de descrever a particularidade de um momento decisivo para o desenvolvimento nacional, do que pela perspicácia ensaística de perceber ali um vetor civilizacional que passaria a compor o modo de fazer política no Brasil, para além daquela circunstância, repercutindo ainda nos nossos dias. Também por isso, o ensaio histórico se potencializa em sua dimensão literária, porque é capaz de transcender à transitoriedade de um instante, por mais contraditório que parecesse, ao menos nas palavras daquele rebento tardio da endogamia cafeeira.

No emaranhado do seu discurso, o próprio Eduardo Prado não sabia aferir a extensão da República recém-instaurada nem o alcance exato de suas formulações. O resultado disso é um desencontro constitutivo da sua expressão, não necessariamente apaziguadora, em face do regime que se consolidava. $\mathrm{O}$ seu artigo se faz, a um só tempo, registro da encruzilhada em que se viu a intelectualidade e a elite brasileira, as quais curiosa e cumulativamente estão representadas no autor, cuja expressão tremula um impasse social, que se confronta com a moralidade vigente. $\mathrm{O}$ veio discursivo aberto por este seu texto se 
ramifica em outros tantos, inclusive àqueles publicados em números posteriores da mesma Revista de Portugal. Mas como até aqui o autor não havia se expressado por meio de um pseudônimo, trata-se, portanto, de um momento anterior à escrita daqueles artigos que vieram a compor o livro Fastos da ditadura militar no Brasil, coligidos inicialmente na Revista de Portugal. No ensaio ora analisado, podemos flagrar um momento em que ainda havia a ilusão ou a esperança de que a monarquia podia ser restaurada, a cuja ilustração segue um parágrafo da segunda parte daquele escrito.

A monarquia, isenta das funestas responsabilidades que hoje lhe dá o encargo inteiro da nação, será a ordem, a paz e a unidade, assentando sobre a base larga e firme da união de províncias fortes e não fracas e descontentes como hoje. A sua influência moral ganhará com o seu progresso e a sua democratização. A missão nacional do povoamento e da utilização do solo será mais rapidamente cumprida e melhor sucedida se, em vez de ser mal dirigida de um ponto único e distante, ela for desempenhada pelas províncias limitando a cada uma os seus esforços, por isso mais eficazes, dentro do próprio território. O elemento estrangeiro é no Brasil a civilização. $\mathrm{O}$ imigrante é o professor nacional do trabalho, o fator e o mestre primeiro da produção de riqueza. [...] As províncias ensinarão umas às outras os meios de adiantamento moral e material que forem adotando e em vez da legislação única que trata igualmente coisas e pessoas desiguais, as leis provinciais terão um caráter experimental que falta à legislação uniforme de outros países (Prado, 1889, pp. 490-1).

A utilização do tempo verbal no futuro é indicativa de uma vontade de interferência nos acontecimentos, que ainda parecia possível, fosse pela proximidade do golpe republicano do tempo de publicação do escrito, fosse pela imprecisão do alcance de sua prosa, o fato é que Eduardo Prado fez render a sua prosa por um viés totalmente inusitado, se considerarmos o que se praticava então como 
narrativa histórica ou memorialística e o que foi praticado discursivamente por Eduardo Prado naquele momento hostil para o desenvolvimento sociocultural brasileiro. $\mathrm{O}$ argumento de que a restauração monárquica seria possível, hoje, pode parecer até risível, como se um arranjo na legislação transformasse a relação das províncias entre si e com a corte, o que sugere algo como uma monarquia federativa, e não apenas parlamentar. Difícil é imaginar, a partir daí, uma relação interprovincial, quando houvera uma concentração das fazendas de café, bem como da mão de obra importada, cujo resultado imediato foi o da precedência de umas províncias sobre as outras. Sendo a sua província natal a que mais cresceu, Eduardo Prado só afirma existencialmente o poço de contradições que nunca deixou de ser, ao longo dos seus quarenta anos, notadamente no espaço institucional da política ou da família tradicional da qual proviera, que às vezes se confundiam diante de seus olhos míopes e às vezes se lhe revelavam como instâncias distantes de si, que ele talvez pudesse emendar. Nunca tendo consertado uma coisa nem outra, nunca deixou de incomodar a todos como uma força expressional viva e de uma representação social incomum do mundo que esteve à sua volta, ocasionalmente girando para lados distintos. 


\section{Referências}

FREDERICO DE S. Fastos da ditadura militar no Brasil. Porto: Revista de Portugal, 1890.

HOLANDA, Sérgio Buarque de. "Prefácio". In PETRONE, Maria Thereza Schorer. O barão de Iguape: um empresário da época da Independência. São Paulo: Ed. Nacional; Brasília: INL, 1976, pp. XI-XX.

LEVI, Darrel Erville. A família Prado. São Paulo: Cultura 70, 1977.

NOGUEIRA, Octaciano. "Um homem contra um regime". In FREDERICO DE S. Fastos da ditadura militar no Brasil. São Paulo: Martins Fontes, 2003, pp. IX-XVII.

PAGANO, Sebastião. Eduardo Prado e sua época. São Paulo: O Cetro, 1960.

PRADO, Eduardo. “Destinos políticos do Brasil”. In QUEIRÓS, Eça de (org.). Revista de Portugal, v. 1, pp. 467-91, Porto: Lugan \& Genelioux editores, 1889.

“Os acontecimentos do Brasil". In QUEIRÓS, Eça de (org.).

Revista de Portugal, v. 1, pp. 770-6, Porto: Lugan \& Genelioux editores, 1889.

“O Brasil, fastos da ditadura”. In QUEIRÓS, Eça de (org.). Revista de Portugal, v. 2, pp. 240-58, Porto: Lugan \& Genelioux editores, 1890. 
. "A língua e a literatura”. In LEVASSEUR, Emile. O Brasil. Rio de Janeiro: Bom Texto; Letras e Expressões, 2000, pp. 126-9.

QUEIRÓS, Eça de (org.). Revista de Portugal, v. 1, Porto: Lugan \& Genelioux editores, 1889.

_. Revista de Portugal, v. 2, Porto: Lugan \& Genelioux editores, 1890a.

Revista de Portugal, v. 3, Porto: Lugan \& Genelioux editores, $1890 \mathrm{~b}$.

Revista de Portugal, v. 4, Porto: Lugan \& Genelioux editores, 1892. 